\title{
Somatic Embryogenesis of Some Member Ornamental Genera of Amaryl- lidaceae and Allied Families: the Similarities and Differences
}

\author{
A. Mujib ${ }^{1, *}$, S. Banerjee ${ }^{2}$, M. Maqsood ${ }^{1}$ and P. D. Ghosh ${ }^{3}$ \\ ${ }^{I}$ Cellular Differentiation and Molecular Genetics Section, Department of Botany, Hamdard University, New Delhi - \\ 110062, India; ${ }^{2}$ CSIRO Publishing, Melbourne, Victoria 3066, Australia; ${ }^{3}$ Department of Genetics, University of Kaly- \\ ani, Kalyani, West Bengal-741 235, India
}

\begin{abstract}
Somatic embryogenesis has been employed in various basic and applied studies such as cellular differentiation of plants, generating transgenic en masse and for mass propagation of elite, endangered and ornamental plants. The studies undertaken in some monocot genera (Eucharis, Hippeastrum, Crinum, Caladium, Gloriosa and Allium) suggest that in vitro embryogeny may also help in establishing relationship among plants, plant groups of similar or dissimilar history. The investigated plants are a few representative monocotyledonous genera, belonging to closely-related families in which in vitro embryogenesis was studied. The observations indicated that Eucharis and Hippeastrum, member genera of the family Amaryllidaceae showed similarity, while Crinum of the same family showed dissimilarities in in vitro embryogeny. In these investigated monocot plants, secondary embryo formations were not observed on primary embryos. Beside embryo ontogeny, the structure and development of embryo, some degrees of similarities in the requirement of plant growth regulator (PGR), especially the BAP's participation $(2.22-4.40 \mu \mathrm{M})$ in embryo formation, presence of embryo dormancy was also noted. The scanning electron microscopy of embryo was conducted and has been presented in this communication. It is envisaged that similar in vitro embryogenesis studies involving plants belonging to different positions in phylogenetic tree would be immensely valuable in future research including in vitro embryogenesis.
\end{abstract}

Keywords: Allium, bulbous, Crinum, Caladium, direct and indirect embryo formation, embryo dormancy, Eucharis, Gloriosa, Hippeastrum, light microscopy, monocot, ornamental, plant growth regulators, scanning electron microscopy, secondary embryo, somatic embryogenesis.

\section{INTRODUCTION}

The first incidence of somatic embryogenesis was described over fifty years back in carrot [1] and since then numerous reports on in vitro embryogenesis were accumulated in literature encompassing monocot, dicot and other groups of plants $[2,3]$. This is a process by which vegetative or somatic plant cell transforms into an embryo that also reconfirms cell's totipotent nature. As this in vitro embryogeny has immense potential not only in investigating plant development from single cells, it has widely been exploited as a unique technique to develop transgenic in masses $[4,5]$. The entire process of somatic embryogeny has been, however, complex and is seemingly controlled by a variety of external and internal triggers. Plant growth regulators (PGRs) are important groups of signaling molecules amongst which auxins are most widely used compounds in initiating embryogenic signals in a numbers of plants [6-8]. These auxins are either used alone or in combinations with cytokinins. The information on addition of cytokinin as the sole source of PGR in inducing embryos in culture is limited $[9,10]$.

Eucharis grandiflora, Hippeastrum hybridum and Crinum asiaticum belong to the family Amaryllidaceae. This

\footnotetext{
*Address correspondence to this author at the Cellular Differentiation and Molecular Genetics Section, Department of Botany, Hamdard University, New Delhi - 110062, India; Tel: +91-11-26059688; Fax + 91-11-26059663; E-mail:amujib3@yahoo.co.in
}

family is an important member of monocotyledon. It contains about sixty genera with over eight hundred species. These are mostly bulbous, rhizomatous and tuberous in nature. Many of the genera are commercially valued for their ornamental applications. A number of these plants are also traded for traditional medicines. In African society, people use bulbs and leaves as decoctions for treating soreness and digestive disorders. The ethnic Zulu people in South Africa use underground plant part as protective charm [11].

In vitro embryogenesis study of Gloriosa superba (Colchicaceae), Allium sativum (Alliaceae / Liliaceae) and Caladium bicolor (Araceae) of three representative families, which are close to Amaryllidaceae was also conducted. $G$. superba contains 5-6 species. The plants are distributed in Africa, Southeastern Asia and many parts of Malaysia [12]. All parts of the plant particularly the tuber contain colchicine and other related alkaloids, which are very toxic when ingested. Various decoctions of the plants are prepared and are used in traditional medicines both in Africa and in India. A. sativum L., commonly known as garlic, is a member of the family Alliaceae. Allium is one of about 57 genera which also contain more than 500 species; this family is recognized as separate from Amaryllidaceae [13]. In other older classification systems, Allium was placed under Liliaceae. It is an important and widely cultivated plant used as a food flavoring agent and it also has several medicinal applications. The active compounds show antibiotic, antitumor, cholesterollowering, and antithrombic effects [14]. Caladium is an im- 
portant group of ornamentals. These araceous plants are distributed in wide areas but the majority of the genera are confined to New World Tropics [15], grown mostly as landscape and potted plants. The genus Caladium consists of 12 distinct species. The plants of this class mostly propagate asexually.

During somatic embryogenesis in dicot, the developing embryos pass through various distinct stages, i.e. globular, heart, torpedo and cotylodonary stages which are very similar to zygotic embryo development. In monocots, however, the stages are different from dicots and can be categorized into globular, scutellar and coleoptilar types [16]. Although the entire process of embryogeny is very complicated and differs many a times, a great deal of similarities in embryo ontogeny, morphology, development and germination still exists within the same or allied groups of plants. It is not very clear that these sub-stages are unique and are conserved only to certain plant groups like Graminae and allied plant genera. Widely divergent plant genera show diversity in embryo form, may be as to propagate in adverse situation during evolution [10].

In the present communication, the pattern of in vitro embryogenesis in a few monocot genera of closely related families was investigated in which the role of PGRs/cytokinin as embryogenic signal in inducing embryo had been compared. The similarities and dissimilarities of embryogenesis were also studied.

\section{MATERIAL AND METHODS}

\section{Plant Materials and Explant Preparation}

The explants, i.e. bulbs, rhizomes/ tubers, flower-buds of plants (Eucharis grandiflora, Hippeastrum hybridum, Crinum asiaticum, Gloriosa superba, Allium sativum, Caladium bicolor) were used as experimental materials. The plants were identified and voucher specimens were preserved and grown at Botanical Survey of India, W.B, India. The authenticated plants have also been propagated at The AgriHorticultural Society of India, Kolkata from which all the explants were taken. Bulbs, rhizomes, flower buds were surface sterilized with $70 \%$ ethyl alcohol for $5 \mathrm{~min}$, followed by $0.1 \%$ mercuric chloride for $4 \mathrm{~min}$, then rinsed with sterilized distilled water three times (each wash was for $2 \mathrm{~min}$ ); the upper portions of the scales were excised and dissected into explants which contained $0.5 \mathrm{~mm}$ stem (condensed basal plate) and about $0.5 \mathrm{~mm}$ fleshy leafy scale, the explants (bulb-scale) were used for culture. In other plants, the underground rhizomes were cut into pieces $(3-5 \mathrm{~mm})$, and were used as explants. Flower-buds were also used as explants for some experiments.

\section{Medium and Culture Conditions}

The explants (bulb-scale, flower bud, and rhizome) of selected plants were placed in Murashige and Skoog (MS) [17] and Knudson C (KC) medium [18]. The bulb-scales were inoculated on medium with the basal stem portion inserted in semisolid medium and the fleshy leaf scale facing up. The rhizome and flower-bud explants were inoculated normally. The media were supplemented with $30 \mathrm{~g} / \mathrm{l}$ sucrose, and 100 mg/l myo-inositol. Different PGRs concentrations each of 2,4-D, NAA, BAP (BA) and Kinetin $(\mathrm{KN})$ were used either alone or in combinations. Coconut water (CW) was also added $(10-15 \% \mathrm{v} / \mathrm{v})$ in some of the experiments. The medium was solidified with $0.8 \%$ agar (Sigma Chemicals Co. St. Louis, MO) and sterilized at $121^{\circ} \mathrm{C}$ for $15 \mathrm{~min}$. The cultures were incubated in the growth room at $25 \pm 2^{\circ} \mathrm{C}$ and $12 \mathrm{~h}$ light regime $\left(50 \pi \mathrm{M} \mathrm{m}^{-2} \mathrm{~s}^{-1}\right.$ Phillips India Fluorescent tubes).

\section{Initiation of Callus and Embryo}

Explants were placed on MS medium supplemented with $30 \mathrm{~g} / \mathrm{l}$ sucrose, and $100 \mathrm{mg} / \mathrm{l}$ myo-inositol. For callus induction, different concentrations of 2, 4-D, NAA, and BAP were used. The presence or absence of early stages of somatic embryos was characterized by small, dense globular or nearly globular structures which were clearly visible with naked eye or with magnifying lenses. The efficiency of PGRs and their concentrations were monitored by observing callus and formation of embryos. The ineffective treatments were discontinued.

\section{Proliferation of Somatic Embryos}

For embryo proliferation, explants bearing embryos or callus with embryos were transferred on MS, added with the same or different levels of PGRs. The embryogenic sectors were maintained well by routine subculturing at 3-4 weeks intervals on the same medium. The embryogenesis percentage and somatic embryo number/ callus mass/ explant were recorded.

\section{Germination of Embryos}

The explants with embryos or embryogenic tissues with developing embryos were used for germination. The medium contained all the essential components of organic and inorganic salts, vitamins, and other basic nutrient of MS. In a few experimental treatments, the medium was additionally added with 1.89-3.78 $\mu \mathrm{M}$ abscisic acid (ABA) and 1.44$2.89 \mu \mathrm{M}$ Gibberellic acid $\left(\mathrm{GA}_{3}\right)$. In another set of experiments, the embryos were kept at low temperature (4 and $10^{\circ} \mathrm{C}$ ) for two weeks. Somatic embryos became green and elongated (matured embryo) while a few of those did not exhibit similar such morpho-physiological changes, the former germinated into plantlets on suitable medium. The somatic embryos numbers that germinated and converted into plants were counted in order to score the germination rate.

\section{Scanning Electron Microscopy (SEM)}

For ontological development study, somatic embryos were examined by Scanning Electron Microscopy (SEM); embryos bearing explants and embryogenic callus with developing embryos were fixed in $2.0 \%$ glutaraldehyde, adjusted to $\mathrm{pH} 6.8$ in $0.1 \mathrm{M}$ phosphate buffer for $24 \mathrm{~h}$ at $4^{\circ} \mathrm{C}$. The tissue was washed in the buffer, post-fixed for $2 \mathrm{~h}$ in similarly buffered $1.0 \%$ osmium tetroxide, dehydrated in a graded ethanol series and finally coated with gold palladium. The prepared samples were examined and photographed in a LEO 435 VP (Zeiss, Oberkochen, Germany) scanning electron microscope operating at $15-25 \mathrm{kV}$.

\section{Transplantation of Plants}

Regenerated somaclones were transferred into $250 \mathrm{ml}$ conical flask containing about $100 \mathrm{ml}$ of $1 / 2 \mathrm{MS}$ with all es- 
sential nutrient elements, 3\% sucrose but without any PGR, and kept under the same cultural conditions as mentioned earlier. Regenerated plantlets were finally transplanted into small plastic pots, filled with soilrite, kept for another one week before transfer to the field.

\section{Statistical Analysis}

The data collected from different experiments were subjected to statistical analysis as to determine the degree of validity of observed responses. The data on the effects of PGRs on callus induction, on embryo formation and germination, other parameters were analyzed by one-way analysis of variance (ANOVAs). Values are means of three replicates from two experiments, and the presented mean values were separated using Duncan's Multiple Range Test (DMRT) at $P$ $\leq 0.05$.

\section{RESULTS}

In Eucharis grandiflora, the embryos originated directly on bulb-scale explants and on the outer rows of scales. Within a week, the cultured bulb-scale swelled and became green on which tiny globular structures appeared on outer wall of scale (not in bulb). The embryos enlarged, turned opaque, and soon became green. Initially, the embryo number was low, but more number of embryos were formed when the embryo bearing explants were routinely cultured on medium amended with same levels of PGRs. Table $\mathbf{1}$ shows that the low concentrations BAP were very effective in inducing embryos in Eucharis, but the addition of NAA particularly at $4.40 \mu \mathrm{M}$ in BAP added medium improved embryo number significantly. Application of NAA alone at different concentrations was, however, ineffective. The embryos were asynchronous in development with varying morphologies (Fig. 1). The embryos were bipolar with shoot and root axis. SEM analysis revealed the embryo well that had swollen base with pointed apical end - a miniature 'mangolike' appearance.

In Hippeastrum hybridum, the origin, development and structure of embryos were very similar to that of $E$. grandiflora. The bulb-scale and flower-bud were used as explants in establishing culture. The embryo formation was direct on explants and was noticed on outer scales. During initiation, embryos appeared as tiny water droplets, gradually enlarged and turned opaque. They often had a swollen base with apical notch. Beside the shoot end, the developed embryos always had a root end at the base (Fig. 1). The induced embryos, although low in number, were matured and germinated into individual plantlets in the same medium while still attached to the mother explants. SEM observations indicated that the embryo was globular in structure at initial stage (Fig. 2a). A light microscopic study of leaf cross section showed that embryos started to originate from the epidermal and sub-epidermal mesophyll cell layers (result not shown). The influence of PGRs on callus induction and on embryo formation is presented in (Table 1). BAP was noted to be

Table 1. Effect of PGRs on Callus Induction and on Embryo Formation in Bulb-Scale Explant of E. grandiflora , H.hybridum , and C.asiaticum

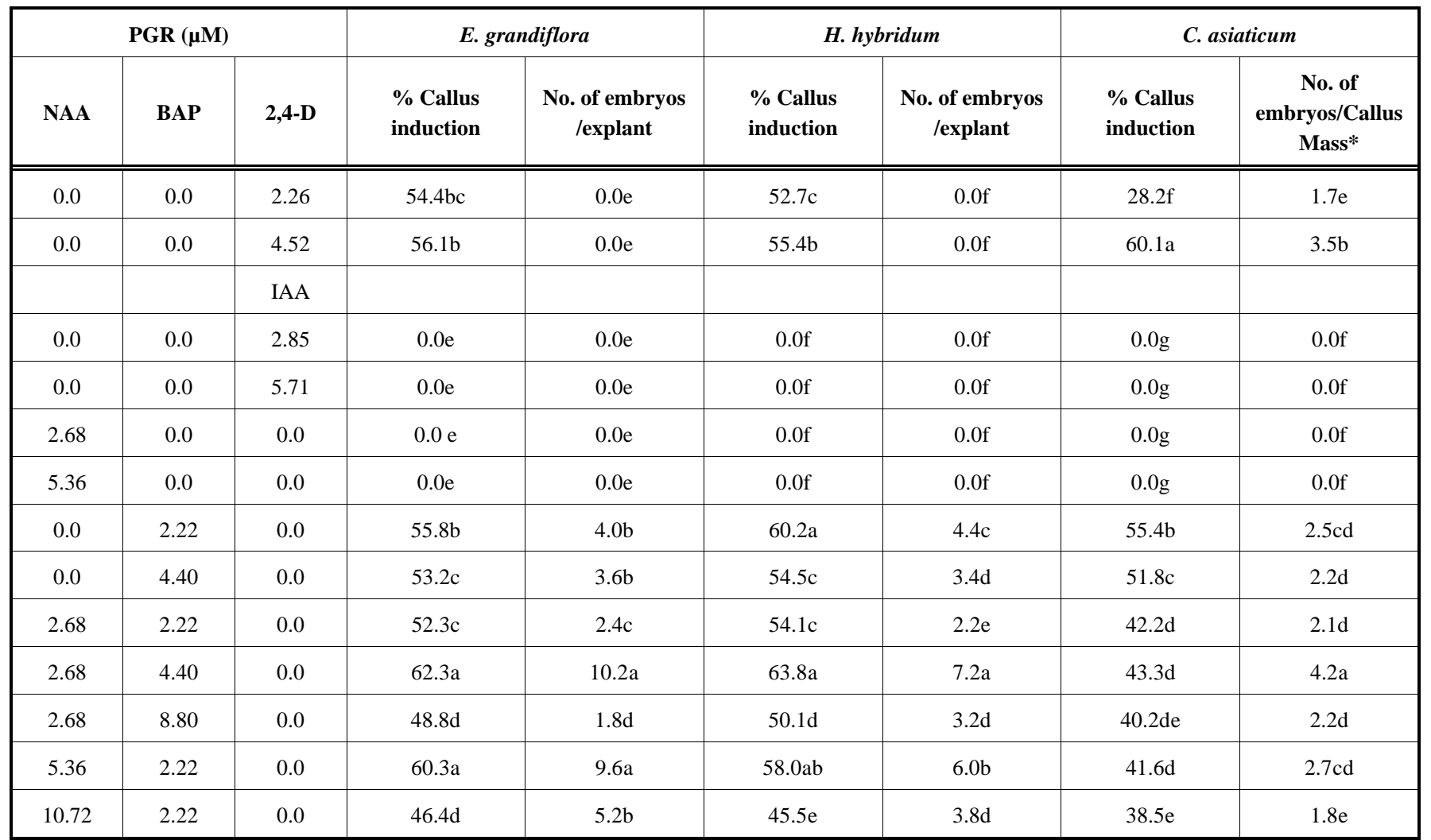

* Flower-bud callus; Data were scored after 6 weeks of culture and the values represent the mean of three replicates of two experiments. Within each column, values are followed by the same superscript letter are not significantly different at $p=0.05$ level according to DMRT. 
very effective in inducing embryos, $2.22 \mu \mathrm{M}$ BAP being the most productive treatment in which average 4.4 embryos were induced. The addition of NAA into the medium increased the embryo number, very similar to $E$. grandiflora. In contrast, various auxins like 2,4-D, IAA and NAA were noted to be inefficient in trigerring embryogenic signal in $H$. hybridum. The embryo-originated plant was separated and grew normally in in vitro conditions.

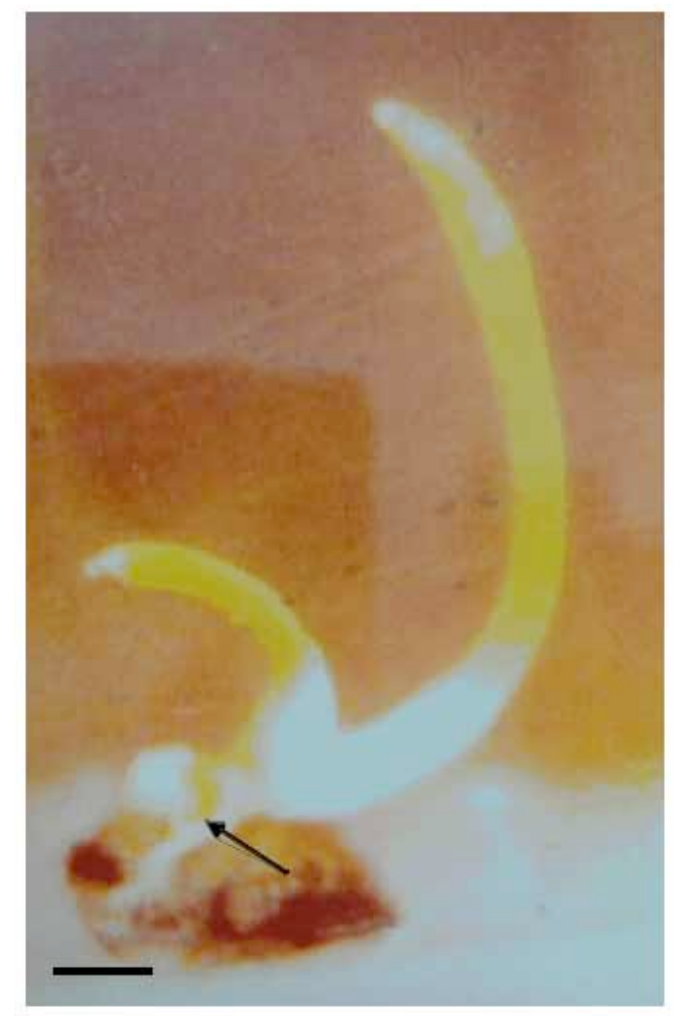

Fig. (1). Germinated somatic embryo of $H$. hybridum, attached to mother explants, root at the base (arrow) $1 \mathrm{~mm}$.

In $C$. asiaticum, bulb-scales and flower-buds were used as explants in MS and $\mathrm{KC}$ media. Both the explants produced callus from their cut ends but the callus induction efficiency and the nature of callus were different. Bulb-scale callus was soft, yellow with red pigment while the flowerbud callus was pale yellow, devoid of such pigment and was slow growing. The high concentrations of 2,4-D were effective in producing callus from bulb-scale while low concentrations promoted callus induction from flower-buds. On bulb-scale calli no case of embryo origin was noted while on flower-bud calli, embryos were differentiated at variable number. Morphologically, the embryos were globular or nearly globular in structure clustered together on a common callus matrix, which turned bipolar, it often had with swollen base and narrowed apex. As the development continued, a small little notch appeared at the median of embryos. Scanning electron microscopy (SEM) examination is presented in (Fig. 2b, 2c) that revealed embryos of various developing stages, crept along callus surfaces. It is clear from the (Table 1) that BAP at low concentration $(2.22 \mu \mathrm{M})$ induced embryos and the embryo forming ability was further improved by enriching the medium with NAA $(2.68 \mu \mathrm{M})$, maximum being at $\mathrm{MS}+\mathrm{BAP}(4.40 \mu \mathrm{M})+\mathrm{NAA}(2.68 \mu \mathrm{M})$.
2,4-D was, however, less responsive for inducing embryos and in the same 2,4-D added medium embryos did not progress into maturity and the plantlet development was very low. In some cases, the induced embryo (basal end) started to show re-callusing.

Morphologically, confirmed by SEM presentation, the somatic embryos of Hippeastrum and Eucharis of family Amaryllidaceae are very similar in structure; developed directly on explants, the development and plantlet formation pattern were also quite same. The origin, structure and the development of Crinum embryos of the same family were, however, different. The embryos had scutellar and coleoptilar appearance, similar to embryos of Graminaceous genera; and the embryos originated on callus i.e. indirectly. In these studied genera (Eucharis, Hippeastrum and Crinum sp) of Amaryllidaceae, no secondary somatic embryo formation was ever noted on primary somatic embryos. The individual use of PGRs like 2,4-D, NAA, IAA which often induced somatic embryos in other plant systems, failed to produce any secondary embryos on primary structures. The application of cytokinin (BAP and Kinetin) was also ineffective in developing embryos. The BAP $(2.22-4.40 \mu \mathrm{M})$ added medium that produced primary somatic embryos did not induce any secondary embryos in culture.

In G. superba, the rhizomatous tubers were used as explants. In 2,4-D added medium the explants showed swelling and the callus started to form within 8-10 days of culture. Some of the rhizome pieces showed early sign of embryo formation directly on explants without any callus formation. Although the frequency was poor $(10-15 \%)$, the embryo formation was more pronounced on medium added with BAP, maximum being in $2.22 \mu \mathrm{M}$ BAP (Table 2), high level was found to be inhibitory. Kinetin, another member of cytokinin, was also found to be less efficient in initiating embryo in culture. Various auxins (2,4-D, IAA and NAA) at different concentrations were also tested as to examine the effect on in vitro embryogenesis in this ornamental plant. None of the used levels of auxins was found effective in forming embryos (results not shown), suggesting thereby their non-signaling role in G. superba. The embryo formation was noted on $2.22 \mu \mathrm{M}$ BAP added medium but the frequency was very poor. Secondary somatic embryo was not observed in any tested conditions including BAP added medium that produced primary somatic embryo.

In A. sativum, the embryos were induced in culture very early. Morphologically, the embryos appeared as shiny, transparent to milky whitish, globular or 'nearly globular' structure; often clustered together on cultured tissues. A SEM examination of embryo is presented in (Fig. 2d). In this plant, a huge diversity in embryo form and structure was observed, most common were cylindrical, elliptical, ovoid and dumbbell shaped. Embryos with one or both polar ends pressed were also noted; a few had 'nearly normal' morphology with reduced hypocotyl and developed shooty end. The type of embryos was therefore, quite different from other studied genera. Both the two different pathways (indirect was more frequent) were operative; the requirement of PGRs level was also different (Table 2). The embryogenesis ability (i.e. the mean number of embryo per explant and the percentage of embryogenesis) was observed in BAP, Kinetin 

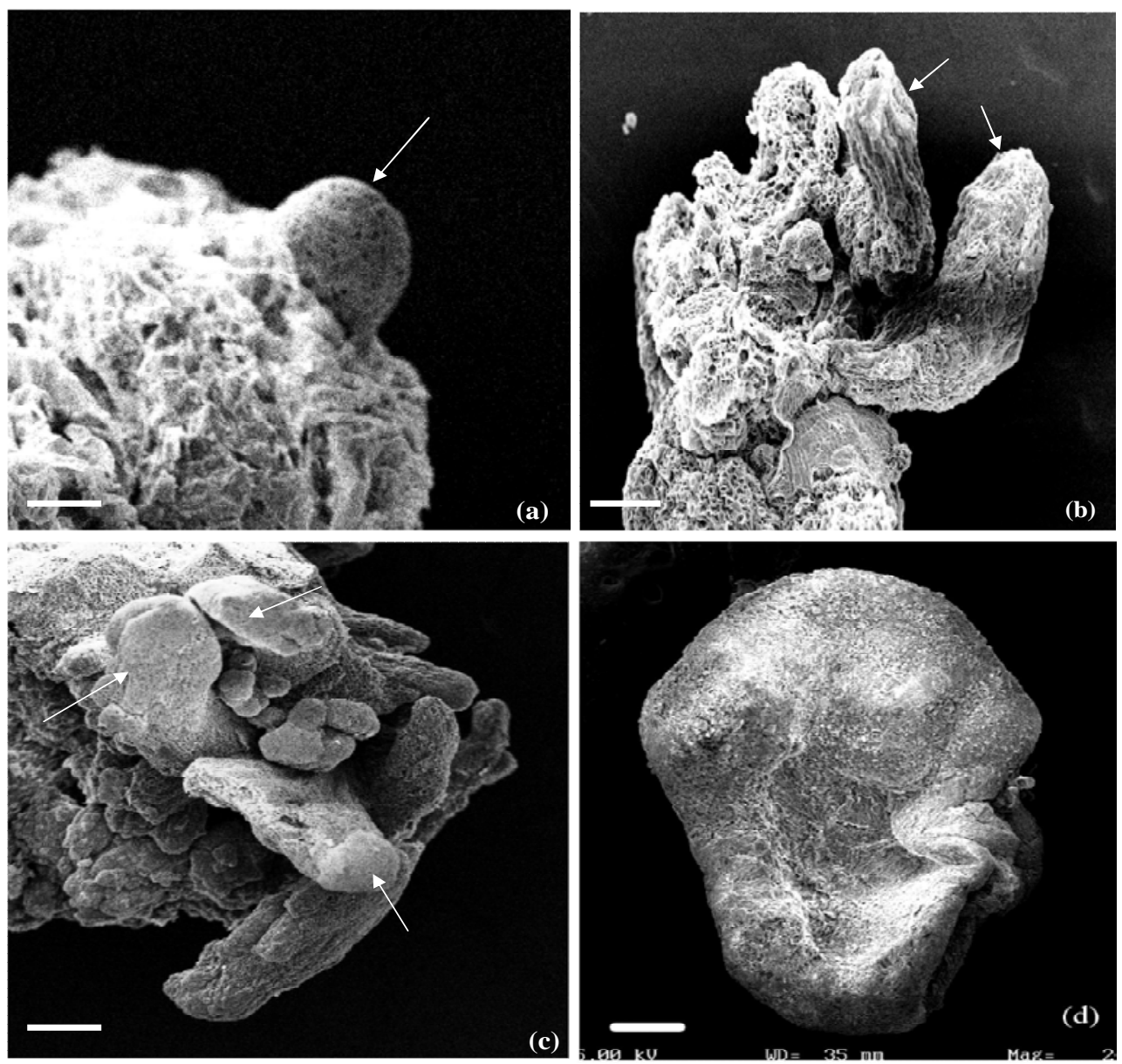

Fig. (2). a) Scanning electron micrograph of a globular embryo (arrow) of Hippeastrum hybridum. b) Scanning electron micrograph of developing somatic embryos (arrows) of Crinum asiaticum. c) Scanning electron micrograph of a cluster of somatic embryos at different stages (arrows) in Crinum asiaticum. d) Scanning electron micrograph of an Allium somatic embryos at early developmental stage. Bars: a,c and d: $500 \mu \mathrm{m}$ b: $1 \mathrm{~mm}$.

Table 2. Effect of PGRs on Callus Induction and on Embryo Formation from Rhizome in G. superba and from Bulb-Scale in A.sativum

\begin{tabular}{|c|c|c|c|c|c|c|}
\hline \multicolumn{3}{|c|}{ PGR $(\mu \mathrm{M})$} & \multicolumn{2}{|c|}{ G. superba } & \multicolumn{2}{|c|}{ A. sativum } \\
\hline 2.26 & 0.0 & 0.0 & $43.7 \mathrm{c}$ & $0.0 \mathrm{~d}$ & 61.0 & $6.0 \mathrm{~d}$ \\
\hline 4.52 & 0.0 & 0.0 & $60.5 \mathrm{a}$ & $0.0 \mathrm{~d}$ & $42.8 \mathrm{c}$ & $5.5 \mathrm{~d}$ \\
\hline 0.0 & 4.40 & 0.0 & $37.7 \mathrm{~d}$ & $1.7 \mathrm{~b}$ & $19.0 \mathrm{~d}$ & $4.5 \mathrm{~d}$ \\
\hline 0.0 & 0.0 & 2.32 & $46.6 c$ & $1.1 \mathrm{c}$ & $51.1 \mathrm{bc}$ & $4.0 \mathrm{~d}$ \\
\hline 0.0 & 0.0 & 4.60 & $50.8 \mathrm{~b}$ & $0.0 \mathrm{~d}$ & $45.0 \mathrm{c}$ & $3.1 \mathrm{~d}$ \\
\hline 1.13 & 8.80 & 0.0 & - & - & $74.2 \mathrm{ab}$ & $21.7 \mathrm{~b}$ \\
\hline
\end{tabular}

*Rhizome callus, ** Bulb-scale callus; Data were scored after 6 weeks of culture and the values represent the mean of three replicates of two experiments. Within each column, values are followed by the same superscript letter are not significantly different at $p=0.05$ level according to DMRT. 
and 2,4-D added medium. The embryo induction frequency was, however, significantly improved on 2,4-D (1.13-4.52 $\mu \mathrm{M})$ and BAP $(8.80 \mu \mathrm{M})$ amended medium. The best PGRs combination identified was $2.26 \mu \mathrm{M} 2,4-\mathrm{D}+8.80 \mu \mathrm{M}$ BAP, which showed maximum embryogenic frequency with highest number of embryos. In this Allium sp. secondary somatic embryo formation was never noted on primary somatic embryo. The single use of 2,4-D often producing secondary embryos in other groups of plants, was found inefficient here in Allium, and so had the cytokinin BAP and Kinetin. In BAP $(8.80 \mu \mathrm{M})$ and 2,4-D (1.13-4.52 $\mu \mathrm{M})$ amended medium in which primary somatic embryos were produced in plenty, no secondary embryo formation was noted.

In Caladium bicolor, the rhizome-callus was hard and compact while leaf induced callus was friable and fast growing. Two-three weeks old rhizome-callus started to produce embryos; at early stage the embryos looked like white ovoid structures with or without root axis, delicately attached to the mother callus tissues. The somatic embryos turned green later (Fig. 3a). Very similar to G. Superba embryo (Fig. 3b) many of the Caladium embryos did not have prominent root axes or with degenerated root end. Embryo formation was primarily noticed on BAP alone $(2.22 \mu \mathrm{M})$ or with NAA $(5.36 \mu \mathrm{M})$ added medium (Table 3$)$. The origin, development and germination of embryos were all completed on embryo induction medium and in no case secondary embryo was formed on primary embryos.

In these plants (E. Grandiflora, H. Hybridum and C. asiaticum), the average time to obtain a plantlet from embryo was about three and half to four months, suggesting thereby a possible 'embryo-dormancy' in somatic embryos. The embryos did not have any seed-coat like protective cover; the factors that delayed embryo germination may thus be present within the embryo itself. We therefore tested $\mathrm{GA}_{3}, \mathrm{ABA}$ and cold treatments for improving embryo physiology in ensuing germination. All the treatments by and large reduced dormancy time but cold treatments have had better influence in shortening embryo dormancy (Table 4). The embryos kept at $4^{\circ} \mathrm{C}$ (for two weeks) germinated early (92.6 days) compared to control (113.3 days), followed by $\mathrm{GA}_{3}$ in which the
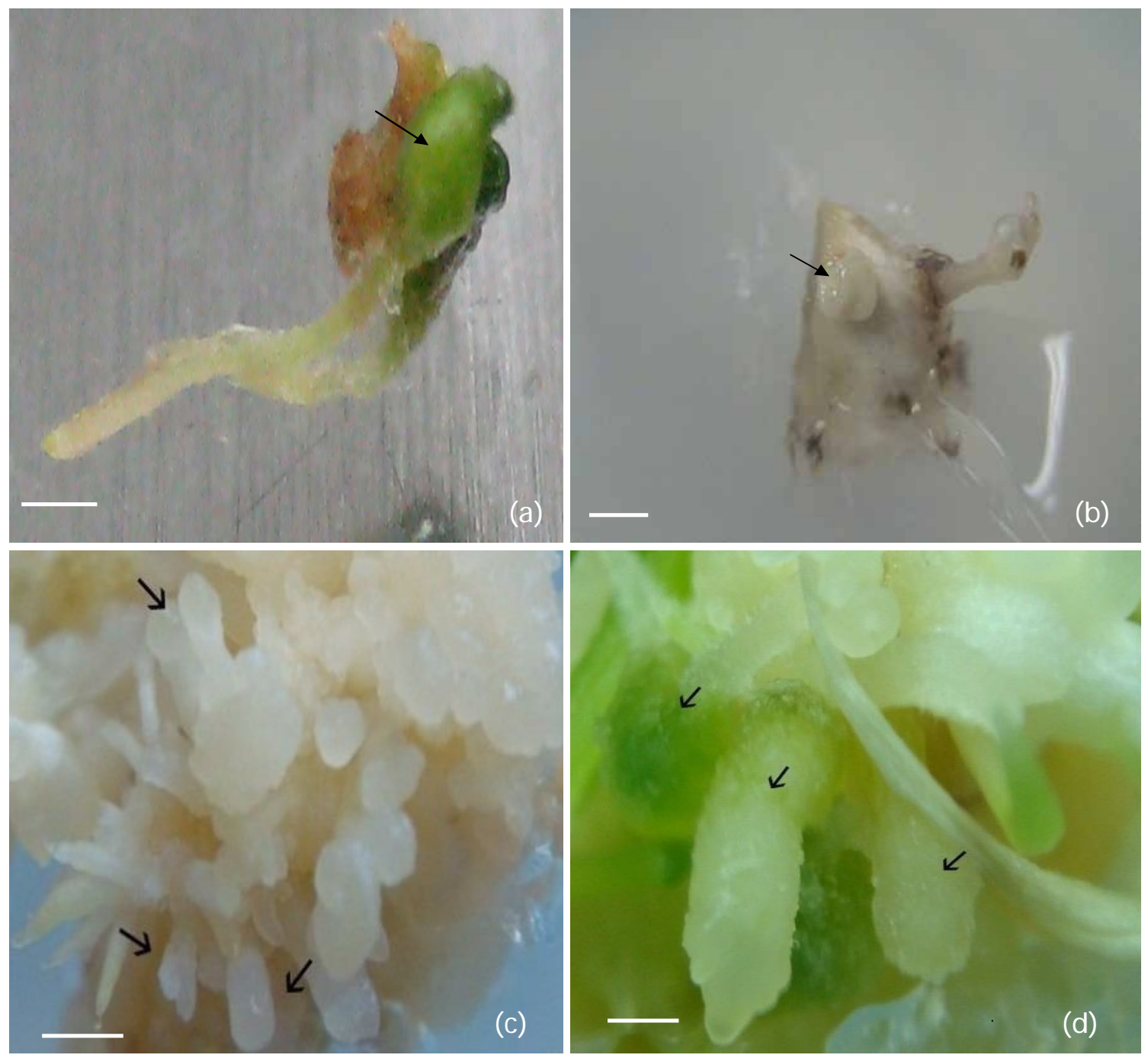

Fig. (3). a) Mature somatic embryo of Caladium bicolor showing long root axis. b) Somatic embryo (arrow) directly induced on rhizome explants of Gloriosa superba. c) Embryogenic callus of Allium sativum showing numerous somatic embryos (arrows). d) Culture showing mature green somatic embryos in Allium sativum (arrows). Bars: a-d: $1 \mathrm{~mm}$. 
Table 3. Effect of PGRs on Callus Induction and on Embryo Formation in Rhizome Explant of C. bicolor

\begin{tabular}{|c|c|c|c|c|}
\hline NAA & BAP & 2, 4-D & $\%$ callus induction & No. of embryos /explant \\
\hline 5.36 & 0.0 & 0.0 & $37.1 \mathrm{f}$ & $0.0 \mathrm{f}$ \\
\hline 0.0 & 2.22 & 0.0 & $48.7 \mathrm{e}$ & $3.6 \mathrm{~b}$ \\
\hline 2.68 & 2.22 & 0.0 & $100.0 \mathrm{a}$ & $1.3 \mathrm{e}$ \\
\hline 5.36 & 2.22 & 0.0 & $93.4 \mathrm{a}$ & $4.5 \mathrm{a}$ \\
\hline 10.72 & 2.22 & 0.0 & $65.3 \mathrm{~d}$ & $2.4 \mathrm{~cd}$ \\
\hline \multirow[t]{2}{*}{0.0} & 0.0 & 4.52 & $63.8 \mathrm{~d}$ & $0.0 \mathrm{f}$ \\
\hline & $\mathrm{Kn}$ & & & \\
\hline 0.0 & 2.32 & 0.0 & $44.2 \mathrm{f}$ & $0.0 \mathrm{f}$ \\
\hline 0.0 & 4.60 & 0.0 & $42.8 \mathrm{f}$ & $0.0 \mathrm{f}$ \\
\hline
\end{tabular}

Data were scored after 6 weeks of culture and the values represent the mean of three replicates of two experiments. Within each column, values are followed by the same superscript letter are not significantly different at $p=0.05$ level according to DMRT.

Table 4. Effect of Various PGRs and Low Temperature Treatments on Somatic Embryo Germination

\begin{tabular}{|c|c|c|c|c|c|c|c|}
\hline \multicolumn{2}{|c|}{ PGR $(\mu \mathrm{M})$} & \multicolumn{2}{c|}{ E. grandiflora } & \multicolumn{2}{c|}{ H. hybridum } & \multicolumn{2}{c|}{ C. asiaticum } \\
\hline \multirow{2}{*}{ BAP } & NAA & Germination \% & $\begin{array}{c}\text { Days for } \\
\text { germination }\end{array}$ & Germination \% & $\begin{array}{c}\text { Days for } \\
\text { germination }\end{array}$ & Germination \% \\
germination
\end{tabular}

Values represent the mean of three replicates of two experiments. Within each column, values are followed by the same superscript letter are not significantly different at $p=0.05$ level according to DMRT.

embryo germination frequency was marginally improved and the average time for embryo germination was also reduced. In cold treatment, provided by low temperature, the levels of photosynthetic reserves (starch, lipid and protein) were high compared to untreated embryos (unpublished). These enriched substances helped fast embryo germination by improving embryo quality.

\section{DISCUSSION}

The Role of 2,4-D / Auxin During Embryogenesis in Studied Plant Genera

In the present study, somatic embryogenesis has been studied in three monocot genera of Amaryllidaceae and a few representative genera of related families in which the role of PGRs has been evaluated. Somatic embryogenesis 
has been earlier reported to be induced by several factors $[19,20]$. PGR is an important group of compounds, often added to the medium to induce embryogenesis. Auxins are the most widely used agents in which the involvement of 2,4-D in embryogenesis was firmly established [7]. In these studied materials three auxins namely 2,4-D, IAA and NAA were used, the latter two auxins had no role whatsoever in inducing embryos in culture while the former 2,4-D was active only in $C$. asiaticum and in A. sativum where low concentration of 2,4-D induced embryos, although poor in number, this herbicide analogue was earlier observed to be essential for induction of callus on which embryos were induced i.e. indirect embryogenesis. In H. hybridum and E. grandiflora, embryo was induced directly on bulb-scale explants but the requirement of 2,4-D and other auxins was not at all necessary. In G. superba and in Caladium bicolor no embryo was formed on 2,4-D or any other auxin added medium. Beside externally added PGRs, the participation and correlation of endogeneous plant hormones with embryogenic competence was earlier established in several other investigated plants including ornamentals [8, 19].

\section{The Effect of Cytokinin}

In contrast to auxins, the role of cytokinins in embryogenesis is not much clear. In most embryogenesis reports, cytokinin was added to the culture medium along with auxins [7]. In some limited cases, cytokinin alone was amended into the medium, quite enough in inducing embryos in culture $[21,22,9]$. In these studied plants, the cytokinin BAP was more active in inducing embryos compared to any other tested cytokinins. It was observed that BAP was successful in H. hybridum, E. grandiflora and in G. superba, $2.22 \mu \mathrm{M}$ BAP was identified as most effective concentration where the explants bulb-scale and rhizome responded well while forming embryos. The number of embryos was not, however, too high in $C$. asiaticum. The embryogenesis frequency and the embryo number increased when the BAP added medium was further enriched with NAA. It was observed that 2.22 and $4.40 \mu \mathrm{M}$ BAP were specifically very effective in generating embryos in three studied materials. Surprisingly, NAA alone in medium had absolutely no role in embryo induction program. The molecular link between embryogenesis and PGRs especially cytokinins has not been clearly established. It has recently been observed that these PGRs regulated cell cycle and gene expression [23], two important steps to initiate embryogenesis. The cyclin gene (a key regulatory subunit which controls cell cycle progression) is very sensitive and is being regulated by cytokinin that promoted cell cycle progression [16]. Although the auxin modulated gene expression during in vitro embryogenesis has been reported in last few years $[24,25]$ the information on cytokinin mediated gene regulation (up and down) has still been inadequate. In these investigated plants, however, the relationship of embryogenesis with cytokinin is clearly established, whether cytokinin like BAP acts simply as stimuli in triggering embryogenic fate or it mediates gene expression by conveying signals still needs to be explored.

\section{Secondary Somatic Embryogenesis: Not Influenced by PGRs, Perhaps Controlled by Inherent Genetic Make-Up}

Secondary or adventive embryogeny has often been associated with primary embryos, and this incidence has been reported in a number of dicotyledonous plants [26, 27]. 2,4$\mathrm{D} /$ auxin which induces primary embryos, routinely induced secondary embryos in short and long term culture that improves the possibility of obtaining more number of embryos than into plantlets. In our studied plant genera (Eucharis, Hippeastrum, Crinum, Gloriosa, Allium and Caladium) secondary somatic embryogenesis program was never switched on primary structures. A variety of PGRs involving 2,4-D, NAA, IBA and IAA (unpublished), and cytokinins BAP, Kinetin and 2ip (unpublished) and one growth adjuvant coconut water was tested. The cultures / explants were kept especially on PGRs at the same level where primary embryo structures were produced; similarly, other PGR combinations were also evaluated to induce secondary embryos in culture. Unfortunately, no secondary embryo was ever formed at any experimental conditions. In long term cultures, gradual shift of PGRs has often been encountered that in turn influenced plant embryogenesis [6, 28-30]. In these experimental materials, cultures kept on medium with or without regular subculturing for extended period of time did not turn on secondary or adventive embryogeny either; we therefore suggest that in these plant groups, the genetic makeup perhaps controlled secondary embryogenesis; and the added plant growth regulator level in the medium had practically no role in secondary embryogenesis program, as in contrast to primary embryogenesis.

The embryos were treated with $\mathrm{GA}_{3}, \mathrm{ABA}$ and cold treatment for promoting embryo germination. Cold treatments have had more influence in shortening dormancy compared to other applied treatments. The mechanism by which low temperature confers tolerance and improves embryo's germination is still not well elucidated. In our study, extra accumulation of starch, lipid and protein was noted in matured embryo compared to other untreated embryos (unpublished). The observation is very similar with earlier study in which cold-stored embryo showed enhanced levels of photosynthetic reserves like lipid, starch and protein [31]. The opposite is also true and observed in some studied plant genera in which lower temperature reduced reserve accumulation during embryo maturation [32, 33]. A reduction of storage reserves was not observed to decrease embryo conversion but the enhanced level of compounds were noted to improve embryo quality in showing embryo germination [34].

It was observed that Eucharis and Hippeastrum, member genera of the same family Amaryllidaceae showed similarity in in vitro embryogeny process while the other genera Crinum of the same family demonstrated dissimilarity in embryo origin (indirect), embryo numbers, germination and in requirement of PGRs. Therefore it needs more study as to confirm its current position and status within the family Amaryllidaceae. Allium, a genus of related family (Alliaceae / Liliaceae) exhibited a huge diversity in embryo structure and form (Fig. 3c, 3d) compared to other studied genera. The embryo's diversity in Allium may perhaps evolve during evolution and is conserved. The embryo morphology in Gloriosa although looks similar to other investigated genera, the number, frequency, and germination behavior of embryo were still different. Caladium somatic embryo structure was also little different. The phenomenon of secondary embryogenesis on primary embryos, a common development in di- 
cot, was not switched on in any of the studied six genera, spread over to four different related families of monocot. The developmental mode of embryos in studied monocot genera is very similar to zygotic embryogenesis where secondary embryogenesis is entirely absent.

\section{CONCLUSION}

Somatic embryogenesis has been considered a unique system to study cellular differentiation in plants in which many of the mechanisms controlling in vitro embryogeny are known. But this is still an important area of research because of diversity in embryogenesis process, the underlying controlling factors and their applications in basic and applied research. A relationship of cells that forms embryo in response to PGRs' signaling and/or in coordination with modulation in specific gene expression needs to be investigated and extended in other groups of plants. The study represented here indicated that there is enough similarity in embryo origin and development, in the requirement of same types of PGR especially the BAP, absence of secondary embryogenesis, and presence of embryo dormancy in these monocotyledonous groups of plant. Similar in vitro embryogenesis analysis involving plants belonging to closely-or distantly-related families or even plants within the same family will therefore, enrich in vitro embryogenesis literature and could shed light on the evolutionary link among plants, plant groups of similar or dissimilar ancestry.

\section{CONFLICT OF INTEREST}

The author(s) confirm that this article content has no conflicts of interest.

\section{ACKNOWLEDGEMENT}

The first author is highly thankful to Indian council of Agricultural Research (ICAR), University Grant Commission (UGC) and Department of Botany, Hamdard University (Jamia Hamdard) for providing financial assistance and facilities. The first author also acknowledges the help, rendered by present and past research students.

\section{ABBREVIATIONS}

$$
\begin{array}{ll}
2,4-D & 2,4-\text { Dichlorophenoxyacetic acid } \\
\mathrm{BA} / \mathrm{BAP} & =6 \text {-Benzyladenine } \\
\mathrm{CW} & =\text { Coconut water } \\
\mathrm{GA}_{3} & =\text { Gibberellic acid } \\
\mathrm{IAA} & =\text { Indole Acetic Acid } \\
\mathrm{KC} & =\text { Knudson } \mathrm{C} \\
\mathrm{KN} & =\text { Kinetin } \\
\mathrm{MS} & =\text { Murashige and Skoog } \\
\mathrm{NAA} & =\alpha-\text { Naphthalene acetic acid } \\
\text { PGR } & =\text { Plant growth regulator }
\end{array}
$$

\section{REFERENCES}

[1] Reinert J. Morphogenese und ihre kontrolle an gewebekulturen aus karotten. Naturwissenschaften 1958; 45: 344-5.
[2] Thorpe TA. In vitro embryogenesis in plants. Dordrecht: Kluwer 1995.

[3] Mujib A, Samaj J. Somatic embryogenesis. Berlin Heidelberg, New York: Springer Verlag 2006.

[4] Rommens CM, Humara JM, Ye J, et al. Crop improvement through modification of the plant's own genome. Plant Physiol 2004; 135: 421-31.

[5] Walter C. Genetic engineering in conifer forestry: technical and social consideration, I in vitro. Cell Dev Biol- Plant 2004; 40: 43441.

[6] Raemakers CJJM, Jacobsen E, Visser RGF. Secondary somatic embryogenesis and applications in plant breeding. Euphytica 1995; 81: 93-107.

[7] Gaj MD. Factors influencing somatic embryogenesis induction and plant regeneration with particular reference to Arabidopsis thaliana (L.) Heynh. J Plant Growth Regul 2004; 43: 27-47.

[8] Jiménez VM, Thomas C, Participation of plant hormones in determination and progression of somatic embryogenesis. In: Mujib A, Samaj J, Eds, Somatic Embryogenesis. Heidelberg: SpringerVerlag 2006; pp. 103-18.

[9] Iantcheva A, Barbulova A, Vlahova M, et al. Regeneration of diploid annual medics via direct somatic embryogenesis promoted by thidiazuron and benzylaminopurine. Plant Cell Rep 1999; 18: $904-$ 10 .

[10] Mujib A, Banerjee S, Ghosh PD. Origin, development and structure of somatic embryo in selected bulbous ornamentals: BAP as inducer. In: Mujib A, Samaj J, Eds, Plant Cell Monographs, Heidelberg: Springer-Verlag 2006; vol. 2: pp. 15-24.

[11] Snijman DA, Linder HP. Phylogenetic relationships, seed characters, and dispersal system evolution in Amaryllideae (Amaryllidaceae). Ann Mo Bot Gard 1996; 83: 362-86.

[12] Smith AC. Flora Vitiensis nova., a new flora of Fiji. Lawai, Kauai, Hawaii: National Tropical Botanical Garden, 1979; 1.

[13] Knud R. Alliaceae. In: Klaus K, Ed. The Families and Genera of Vascular Plants., vol. III. Berlin, Heidelberg: Springer-Verlag, 1998.

[14] Milner JA. A historical perspective on garlic and cancer. J Nutr 2001;131 (3s): 1027S-31.

[15] Bown D. Aroids- plants of the Arum family. Oregon: Timber Press, 1988.

[16] Thomas C, Jiménez VM. Mode of action of plant hormones and and plant growth regulators during induction of somatic embryogenesis: molecular aspects. In: Mujib A, Samaj J, Eds, Somatic Embryogenesis. Heidelberg: Springer-Verlag 2006; pp.157-75.

[17] Murashige T, Skoog F. A revised medium for rapid growth and bioassays with tobacco tissue cultures. Physiol Plant 1962; 15: 47397.

[18] Knudson L. Nutrient solution for orchids. Bot Gaz 1951; 112: 52832.

[19] Jiménez VM. Regulation of in vitro somatic embryogenesis with emphasis on the role of endogenous hormones. Rev Bras Fisiol Veg 2001; 13: 196-223.

[20] Fehér A, Pasternak TP, Dudits D. Transition of somatic plant cells to an embryogenic state. Plant Cell Tissue Org Cult 2003; 74: 20128.

[21] Malik K, Saxena PK. Regeneration in Phaseolus vulgaris L.: High frequency induction of direct shoot formation in intact seedlings by BAP and TDZ. Planta 1992; 186: 384-8.

[22] Bronner R, Jeannin G, Hahne G. Early cellular events during organogenesis and somatic embryogenesis induced on immature zygotic embryos of sunflower (Helianthus annuиs). Can J Bot 1994; 72: $239-48$

[23] Francis D, Sorrell DA. The interface between the cell cycle and plant growth regulators: a mini review. Plant Growth Reg 2001; 33 $1-12$.

[24] Ulmasov T, Hagen G, Guilfoyle TJ. Activation and repression of transcription by auxin-response factors. Proc Natl Acad Sci USA 1999; 96: 5844-9.

[25] Kitamiya E, Suzuki S, Sano T, Nagata T. Isolation of two genes that were induced upon the initiation of somatic embryogenesis on carrot hypocotyls by high concentrations of 2,4-D. Plant Cell Rep 2000; 19: 551-7.

Junaid A, Mujib A, Bhat MA, et al. Somatic embryogenesis and plant regeneration in Catharanthus roseus. Biol Plant 2007; 51: 641-6. 
[27] Karami O, Deljao A, Pour AM. Repetitive somatic embryogenesis in carnation in picloram supplemented media. Plant Growth Reg 2007; 51: 33-9.

[28] Cooke TJ, Racusen RH, Cohen JD. The role of auxin in plant embryogenesis. Plant Cell 1993; 5: 1494-5.

[29] Thorpe TA. Somatic embryogenesis: morphogenesis, physiology, biochemistry and molecular biology. Korean J Plant Tissue Cult 2000; $27: 245-58$.

[30] Aloni R, Schwalm K, Langhans M, et al. Gradual shifts in sites of free-auxin production during leaf-primordium development and their role in vascular differentiation and leaf morphogenesis in Arabidopsis. Planta 2003; 216: 841-53.

[31] Attree SM, Pomeroy MK, Fowke LC. Manipulation of conditions for the culture of somatic embryos of white spruce for improved triacylglycerol biosynthesis and desiccation tolerance. Planta 1992; 187: 395-404.

[32] Haggman H, Jokela A, Kranjnakova J, et al. Somatic embryogenesis of Scots pine: cold treatment and characteristics of explants affecting induction. J Exp Bot 1999; 50: 1769-78.

[33] Klimaszewska K, Monency F, Jones-Overton C, et al. Accumulation pattern and identification of seed storage proteins zygotic embryos of Pinus strobes and in somatic embryos from different maturation treatments. Physiol Plant 2004; 121: 682-90.

[34] Patrick von A, Lisheng K, Barbara $\mathrm{H}$, et al. Effects of non-freezing low temperatures on quality and cold tolerance of mature somatic embryos of interior spruce. Prop Ornament Plants 2007; 112-21.

(C) Mujib et al.; Licensee Bentham Open.

This is an open access article licensed under the terms of the Creative Commons Attribution Non-Commercial License (http://creativecommons.org/licenses/by-nc/3.0/) which permits unrestricted, non-commercial use, distribution and reproduction in any medium, provided the work is properly cited. 